\section{Northern Canadian Indigenous and the environment}

\section{A relationship compromised by colonization and cli- mate change.}

\author{
BY COLIN JAMIESON
}

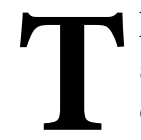
he environment is a complex system comprised of social, cultural, and natural forces that can regularly influence one's health and wellbeing. It has power over both opportunity and behavior and has historically led to human adaptation. This is particularly true among Indigenous populations of Canada. Canadian Indigenous peoples share a strong, longstanding relationship with the natural environment and have been driven to adapt as a result of colonialism, systemic oppression and exclusion, forced displacement, and climate change [1-3]. Harmony between humans and the natural world is highly revered among Indigenous communities. Indigenous peoples often rely on the natural environment for sustenance and in return they cherish and respect it [4-5]. This harmonious relationship is often seen as a fundamental component of Indigenous culture; in fact, many Indigenous peoples integrate environmental health into their sense of wellness or personal well-being [6]. Andrew Papadopoulos, an associate professor in population medicine at the University of Guelph, explained that Indigenous peoples often "look at the absence of caribou, the rising of temperatures, the melting of ice, the presence of trichinella in walruses, and the absence of other traditional food sources" when expressing their wellbeing.

As a result of colonization, Indigenous populations have been distanced from their traditional lands - thereby compromising traditional food practices and the pertinence of local knowledge [5]. Despite contributing little to climate change, these communities have been displaced to regions experiencing the most rapid environmental changes. Rising environmental temperatures at the Canadian Arctic has led to unstable ice conditions and has altered animal migration patterns [7-9]. Traditional Inuit peoples rely on the conditions of the sea ice to enable safe travel to hunting and fishing grounds, and thus, unstable ice conditions have hindered access to traditional food sources. This has led to a growing prevalence of food insecurity colonization. among Inuit households increasing the risk of hunger and malnutrition among these individuals. In fact, a study from McGill University found that food insecurity was three times more prevalent among Inuit compared to off-reserve Indigenous households [1]. A Canadian study also found that increasing sea ice instability has restricted Inuit peoples' freedom of movement, increased physical dangers associated with hunting and fishing, and has significantly disturbed traditional ways of living [5]. Ice trips are associated with social bonding and the transference of traditional knowledge, as climate change has made these trips more dangerous and less practical it has disconnected Inuit peoples from their environment - causing a significant loss of place [5]. Cultural disruption compounded with social isolation and endangered personal safety has resulted in increased levels of stress and worsened mental health among these populations.

When providing Indigenous communities with support, it is vital to build relationships and work in consultation. Papadopoulos stressed the importance of providing "care, treatment, or services in a culturally appropriate manner." In the context of Indigenous communities, it is important to recognize their desire for self-governance and autonomy as well as the importance of tradition within their culture [10-11]. When pathogenic growth occurred in

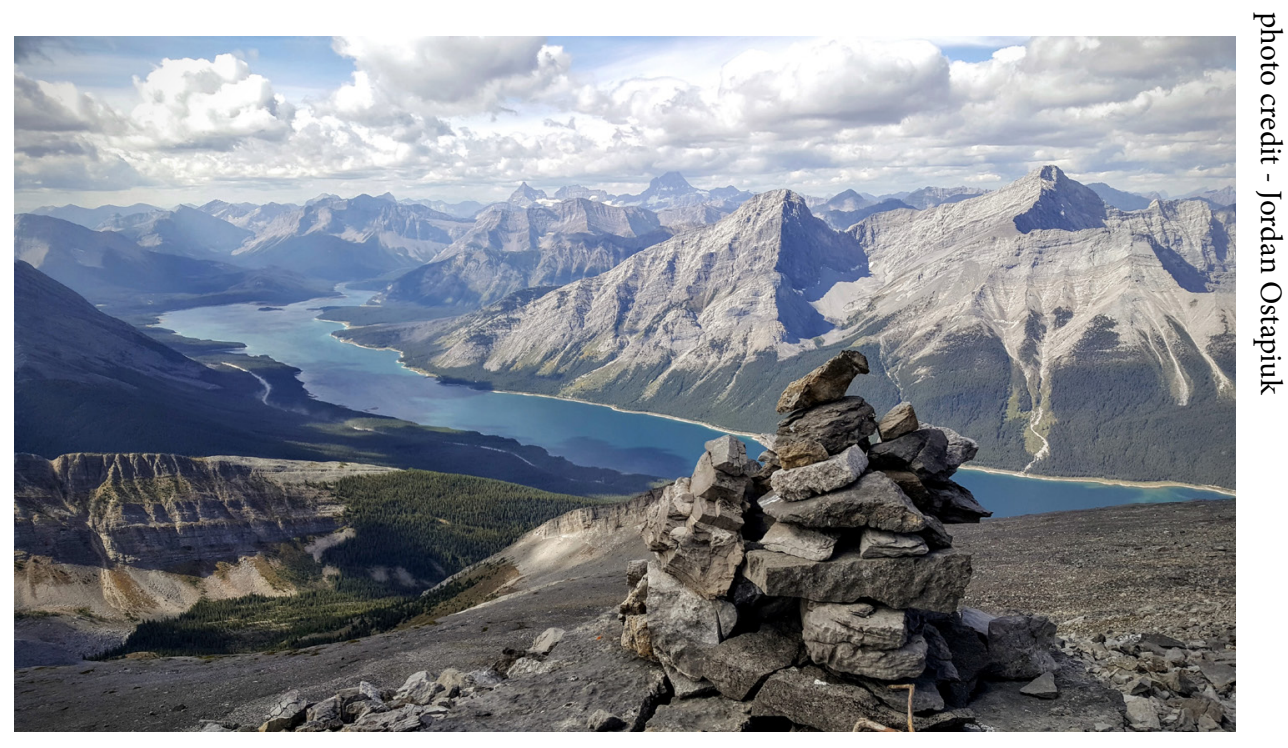

The Bow River in Alberta, Canada - called Makhabn in the Blackfoot language - was used by Indigenous people for travel, hunting, and fishing, long before European 
Northern Canadian water sources due to rising temperatures, water treatment systems were put in to provide potable tap water to Indigenous homes without consultation. However, members of the community continued to rely on contaminated water sources because that was where the community obtained drinking water for generations past. Not only was the government assistance a failure, for Papadopoulos, introducing the water treatment systems without consultation "represents further colonialism," as it may be interpreted as an attempt at assimilation, further distancing these populations from traditional practices.

"It's the balance of how you respect the culture, the desires, and the determinations of the population, without adding to further colonialism and greater repression of these communities," Papadopoulos said.

Canadian researchers, including Papadopoulos, have been attempting to develop culturally appropriate strategies to aid in Indigenous adaptation to climate change. These approaches have tended to utilize some form of collaborative, community-based mon- from one another and generate culturally appropriate strategies.

"Indigenous communities prefer to communicate orally, face to face, primarily through elders and more knowledgeable individuals within the community down to younger members," Papadopoulos said. In line with this preferred means of communication Papadopoulos and his colleagues have established several means of public health transmission including digital story telling for Canadian Inuit communities $[14,15]$. Younger members of the community would record elders explaining a message about healthy behaviors and how they interpret health and wellbeing. This video can than be uploaded to a website and shared among other Northern communities across Canada relieving the barrier of travel.

"[This created spaces for] elders to express what wellness means to them and what others can learn from the message that they are presenting," Papadopoulos said. "It was community-driven and supported by researchers."

Digital story telling parallels traditional word of mouth transmission and is an example of a collaborative, culturally appropriate strategy in which Indigenous community members and public health researchers can effectively disseminate information. This platform can be used to disseminate information regarding adaptations to climate

itoring, where members of Indigenous communities were actively involved in the monitoring of environmental change [2]. Firstly, traditional knowledge can help contextualize scientific observations and better scientific understanding of the local impacts of climate change. Secondly, actively working with Indigenous members in climate research and its dissemination has been shown to significantly improve the translation of research findings into practical action [12]. Through collaboration both public health researchers and Indigenous communities can learn perspectives [14]. The most essential aspect was that the Indigenous partners were able to lead these projects and present these messages in a way that best matches the needs of their cultural environment. For not only can one's environment have a direct influence on health in terms of mental stresses, access to food or clean water, but also indirectly through the transmission of health knowledge and awareness of healthy behaviors.

The environment can great-

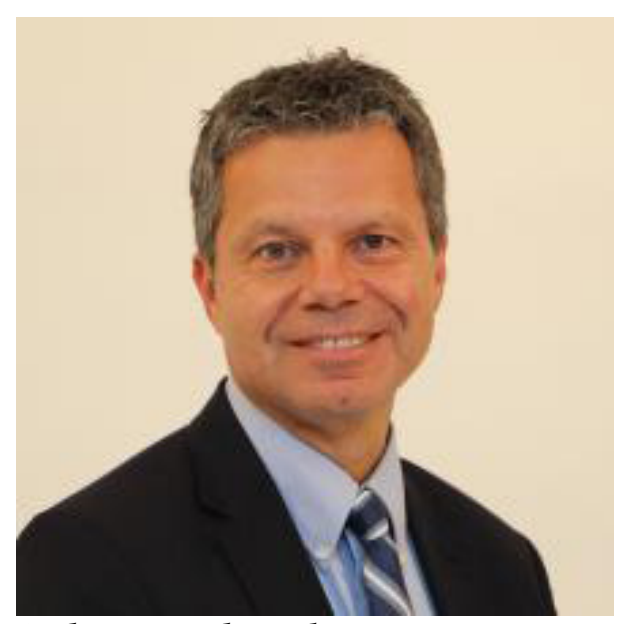

Andrew Papadopoulos

ly impact one's health and wellbeing. This can occur directly through the disruption of healthy behaviors or indirectly through communication of these behaviors. However, these effects are extremely culturally dependent. Different cultures possess different values and priorities; therefore, it is essential to address impacts through a culturally dependent lens $[2,3,6,12]$. Papadopoulos explained that it's important for researchers, public health officials, or members of the government to recognize the specific values of communities and provide support in an appropriate manner. A lot can be learned from Indigenous tradition and local knowledge especially in the context of environmental change [12].

"A better understanding of cultural traditions and Indigenous values and allowing Indigenous communities to work with us or guide us in helping them, is going to be an area where we see some great benefits long-term," Papadopoulos said.

\section{REFERENCES}

1. Huet C, Rosol R, Egeland, GM. The prevalence of food insecurity is high and the diet quality poor in Inuit communities. The Journal of Nutrition. 2012; 142(3): 541-547.

2. Lam S., Dodd W, Skinner K, Papadopoulos A, Zivot, C, Ford J, ... Harper, S. L. Community-based monitoring of Indigenous food security in a changing climate: global trends and future directions. Environmental Research Letters 2019; 14(7), 073002.

3. Ford JD, Willox AC, Chatwood S, Furgal C, Harper S, Mauro, I, Pearce, T. Adapting to the Effects of Climate Change on Inuit Health. American Journal of Public Health 2014; 104(S3). 
4. Downing, A, Cuerrier A. A synthesis of the impacts of climate change on the First Nations and Inuit of Canada. Indian Journal of Traditional Knowledge 2011; 10(1): 57-70.

5. Durkalec A, Furgal C, Skinner MW, Sheldon T. Climate change influences on environment as a determinant of Indigenous health: Relationships to place, sea ice, and health in an Inuit community. Social

Science \& Medicine 2015; 136-137, 17-26.

6. Kimmerer, R. W. (2020). Braiding sweetgrass: indigenous wisdom, scientific knowledge and the teachings of plants. London: Penguin Books.

7. Ford J. Indigenous health and climate change. American Journal of Public Health 2012; 102(7): 1260-1266.

8. Whyte K. Indigenous climate change studies: Indigenizing futures, decolonizing the anthropocene. English language notes 2017, 55(1-2), 153-162.

9. Harper SL, Edge VL, Schuster-Wallace
CJ, Berke O, Mcewen SA. Weather, Water Quality and Infectious Gastrointestinal Illness in Two Inuit Communities in Nunatsiavut, Canada: Potential Implications for Climate Change. EcoHealth 2011; 8(1): 93-108.

10. Reid M, Hamilton C, Reid S, Trousdale W, Hill C, Turner N, ... Matthews D. Indigenous climate change adaptation planning using a values-focused approach: A case study with the Gitga'at nation. Journal of Ethnobiology 2014; 34(3): 401-424.

11. Lavoie JG, Kornelsen D, Wylie L, Mignone J, Dwyer J, Boyer Y, ... Odonnell K. (2016). Responding to health inequities: Indigenous health system innovations. Global Health, Epidemiology and Genomics 2016; 1 .

12. Alexander C, Bynum N, Johnson E, King U, Mustonen T, Neofotis P, ... Weeks B. Linking indigenous and scientific knowledge of climate change. BioScience 2011; 61(6): 477-484.
13. McDonald ME, Papadopoulos A, Edge VL, Ford J, Sumner A, Harper SL. (2016). What do we know about health-related knowledge translation in the Circumpolar North? Results from a scoping review. International Journal of Circumpolar Health 2016; 75(1): 312-23.

14. McDonald E, Papadopolous A, Harper S. (2015). Retrieved from https://atrium2.lib.uoguelph.ca/xmlui/bitstream/ handle/10214/9265/McDonald_MargaretE_201509_MSc.pdf?sequence=1\&isAllowed=y Saini M, Roche S, Papadopoulos A.

15. Markwick N, Shiwak I, Flowers C, ... Harper SL. Promoting Inuit health through a participatory whiteboard video. Canadian Journal of Public Health 2019; 111(1): 50-59.

\section{Climate change and human health}

\section{The choice between surviving and thriving.}

\section{BY LING WU \& HUGH MONTGOMERY}

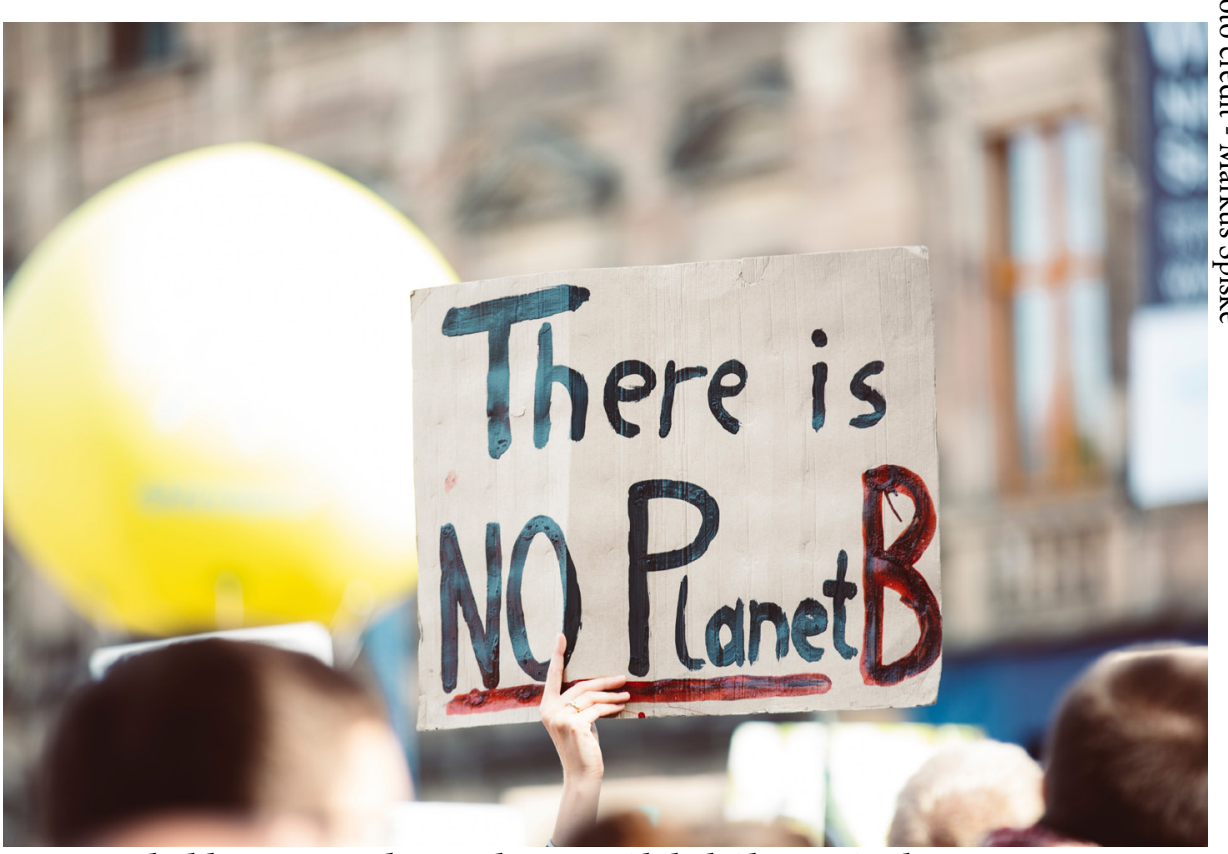

Protestor holds up a sign during the 2019 Global Climate Strike in Eriangen, Germany

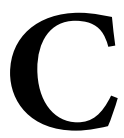
limate change is the greatest and most unprecedented challenge we are facing in the 21st century: one that threatens every facet of life upon which we rely. There is increasing evidence of the profound impact of climate change on human health including consequences of extreme weather events, and most pressingly, newly emerging patterns of infectious disease. The severe impacts of global climate change on public health requires the sustainable action of individuals, businesses, and governments to shoulder the responsibility of preventing a rise in global temperatures. Most importantly, this involves reaching the societal targets of the Paris Agreement - keeping average temperatures below two degrees Celsius above pre-industrial levels[1].

In Geneva, the first World Health Organization [WHO] Global Conference on Air Pollution and Health was held in 2018. The chief aim of which was to catalyze a global response against air pollution, associated disease exposures, and overall cost to society [2]. This same objective is echoed by the Lancet Countdown on Health and Climate Change [LCHCC], an annual, international, and multidisciplinary report that highlights and monitors the evolving landscape of health in the era of climate change [3]. In its 2019 report, the LHCC addressed our pressing fight with climate change as "an unprecedented challenge" that "demands an unprecedented response." 